\title{
Successful Vaginal delivery of locked twin in a tertiary care centre of Western region of Nepal
}

\author{
Pandey MR, ${ }^{1 *}$ Ghimire $P^{2}$ Ghimire $P^{3}$
}

\author{
${ }^{1}$ Department of Obstetrics and Gynecology, Manipal Teaching Hospital, Pokhara, Nepal, ${ }^{2}$ House Officer, Department of \\ Surgery, Western Regional Hospital, Pokhara, Nepal, 3 Intern, Manipal Teaching Hospital, Pokhara, Nepal
}

\author{
*Corresponding Author: \\ Dr. Mahendra Raj Pandey \\ Lecturer, Department of Obstetrics and Gynaecology \\ Manipal Teaching Hospital, Pokhhara, Nepal \\ Email: sarkar_mrp@yahoo.com \\ Citation \\ Pandey MR, Ghimire P, Ghimire P. Successful Vaginal \\ delivery of locked twin in a tertiary care centre of \\ Western region of Nepal. Nepal Journal of Medical \\ Sciences 2014;3(1):74-5
}

\begin{abstract}
Here we report a case of unbooked primigravida who was admitted to the labor room with labor pain. Ultrasonography revealed twin pregnancy with first twin presenting as breech. After coming head of the first breech fetus locked with the head of the second cephalic fetus during labor. Successful Vaginal delivery of both the live fetuses was performed along with mediolateral episiotomy following disengagement of head.
\end{abstract}

Keywords: Breech presentation; locked twins; vaginal delivery

\section{Introduction:}

Locked twins is a form of malpresentation in which a breech twin and a vertex twin become locked at the chin during labour and attempted delivery. ${ }^{1}$ Its incidence has been reported to be $1: 2461$ to 90,000 deliveries and 1:140 to 1000 twin deliveries. ${ }^{2,3}$ since it is such a rare event, even the most busy clinician may not encounter a single case in his/her entire career. Even when such a condition is encountered; it may not be diagnosed early enough to avoid complications. Here we report a case of locked twins which was delivered successfully via vaginal route.

\section{Case report:}

An unbooked primigravida aged 18 years was admitted to labor room of Manipal Teaching Hospital, Pokhara, Nepal, with complains of labor pain with blood tinged minimal per vaginal discharge. Period of Gestation was $30^{+3}$ weeks at the time of admission. On examination, her vitals were stable. Per abdominal examination revealed uterine fundal height of 36 weeks' size with multiple fetal parts felt. Fetal heart rate of both the fetuses 138 beats per minute and 142 beats per minute. Per vaginal examination revealed $2 \mathrm{~cm}$ Os with $50 \%$ effaced soft cervix and intact bag of membranes.

Emergency ultrasound revealed twin pregnancy with Twin 1; breech presentation of 30 weeks 1 day and Twin 2; cephalic presentation of 28 weeks calculated gestational age. The liquor volume was adequate with single large anterior placenta. Labor progressed satisfactorily but during the delivery of the Twin 1 with breech presentation, vaginal examination revealed locked head of the second baby. Disengagement of head was done vaginally and delivery of live Twin 1 weighing $1.4 \mathrm{~kg}$ was done followed by live Twin 2 weighing $1.3 \mathrm{~kg}$ vaginally after mediolateral episiotomy. The babies were then handed over to pediatrician. Placental examination was consistent with monochorionic monomniotic twin. Both the babies were discharged after 2 weeks of observation by the pediatrician. The mother had an uneventful stay in the hospital and was discharged 
subsequently.

\section{Discussion:}

The prognosis for fetus in locked twins is usually disastrous with high perinatal mortality. The fate of first twin is usually worse than that of second twin. This fact is usually the source of trepidation felt by most clinicians when confronted by the situation of handling a locked twin.

Ultrasonography at term followed by routine Cesarean section in all cases where first twin presents as breech is increasing; but vaginal deliveries in such cases doesn't seem to increase morbidity or mortality. ${ }^{4-6}$ In our case we opted for a trial of labor under supervision of a gynecologist.

Successful outcome in locked twin by the application of Zavanelli maneuver, use of tocolytic has been described. ${ }^{7,8}$ Locking of twins was diagnosed only in the second stage of labor; which is usually the case. It was managed by vaginally disengaging the head of twins. The outcome for both mother and the twins was satisfactory despite of longer hospital stay for the babies.

In resource poor countries like Nepal; it is usual for pregnant ladies to visit a health facility for the first time after labor pain has started. This might be problematic in high risk pregnancies such as this one. Urgent transfer of such cases to a place where emergency ultrasonography, supervision of a gynecologist and facility of emergency cesarean section when required is of utmost importance.

\section{Conclusion:}

Locked twins must be managed in an individual basis. Fetal morbidity and mortality can be avoided by identifying the potential cases, regular antenatal follow up of at risk twin pregnancies, radiological diagnosis, and timely admission and management. Trial of labor can be attempted on favorable circumstances.

\section{References:}

1. Stedman's medical dictionary, $27^{\text {th }}$ edition. Lippincott William \& Wilkins,2003.

2. Parvin: in Hirst BC, ed: A system of Obstetrics by American authors. Lea Brothers \& Co Ltd: Philadelphia1:774;1888.

3. Lister UG. Obstructed labor. A series of 320 cases occurring In 4 years in a hospital in Southern Nigeria. J obstet Gynaecol Brit Emp 1960;67:188-98.

http://dx.doi.org/10.1111/j.1471-0528.1960.tb06978.x

4. Bischopp CNS, Vogelvang TE, May AM, et al. Mode of delivery in non-cephalic presenting twins a systematic review. Arch Gynecol Obstet 2012:286:237-47.

http://dx.doi.org/10.1007/s00404-012-2294-6

5. SentiihesS, Goffinet F, Talbot A, et al. Attempted vaginal versus planned cesarean delivery in 195 breech first twin pregnancy. Acta Obstet Gyanecol Scand 2007;86:55-60.

\section{http://dx.doi.org/10.1080/00016340601089594}

6. Abu-Heiza AT, Ziadeh S, Obeidat A. Mode of delivery and perinatal results from breech first twins. J Obstet Gyanecol 1998;18:47-9.

http://dx.doi.org/10.1080/01443619868271

7. Saad FA, Sharara HA. Locked twins: A successful outcome after applying the Zavanelli maneuver. J Obstet Gynaecol 1997;17:366-7.

http://dx.doi.org/10.1080/01443619750112853

8. Sevitz H, Merrell DA. The use of a betasympathomimetic drug in locked twins. Case report. Br J Obstet Gynaecol 2005;88:76-7.

http://dx.doi.org/10.1111/j.1471-0528.1981.tb00942.x 